\title{
Weapons of Mass \\ Destruction-Conceptual and Ethical \\ Issues with Regard to terrorism
}

\author{
Jonas Feltes
}

\section{Introduction}

The concept of WMD is part of numerous national laws and is the core of one of the most important treaties of the United Nations [51, 64]. Yet, the definition of what should be considered a WMD is far from established and subject to controversial debates. Academics, policymakers, and legislators have been introducing a variety of partly conflicting conceptualizations of WMD into scientific debates, public discourse, and legislations over the last eight decades. Hence, it is unsurprising that this concept and its changing definition have been subject to politicization. Especially in light of the so-called "War Against Terror," WMD became the synonym of a worst-case terrorist attack scenario that ought to be prevented by any means [55]. However, terrorism and other asymmetrical conflicts pose serious challenges to the concept of WMD - serious enough to think about alternatives to this term in case of counter-terrorism discussions. One particular issue stems from the ethical challenges that the label WMD generates if used in combination with terrorism.

This chapter presents the history of the term WMD as well as numerous issues with and alternative approaches to the concept of WMD. In this discussion the concept of CBRN (chemical, biological, radiological, and nuclear) as a prominent interpretation of WMD is of utmost importance. It will be argued that a static concept that includes or excludes certain weapon types purely on the basis of their physical impact in an attack deals with problematic threshold issues and ethical challenges. In this chapter, I discuss concepts of terrorist weaponry that are focused on a more complex account of the impact of each weapon type used by terrorists. Specifically, the impact of

This chapter is part of the author's doctoral dissertation titled "CBRN Threats, Counter-Terrorism, and Collective Moral Responsibility".

J. Feltes (凶)

TPM Faculty, TU Delft, Delft, The Netherlands

e-mail: j.feltes@tudelft.nl 
a weapon type will be assessed by means of analyzing its hard (physical) and soft (psychological, economic, political) damage. Furthermore, the time that is necessary to create a high impact with the one-off use of the weapon, as well as uncertainties with regard to the consequences of the use of said weapon, will be part of the impact assessment.

However, in order to assess the dangers involved in and the severity of specific weapons in the hand of terrorists, it is not sufficient to focus only on the impact of a possible attack with this weapon. For example, even without an elaborate analysis, it is clear that nuclear weapons would easily achieve the highest score in terms of impact. However, the impact of a certain weapon technology does not say much about the terrorist threat posed by this weapon if this technology is simply not available to terrorist groups. Hence, a basic assessment of the resources and other restricting factors that guide the weapon choices of terrorists needs to be part of this chapter as well. This assessment might show a trend that is diametrically opposed to the impact of specific weapon technologies. It includes, for example, factors like accessibility, required expertise, operational space needed as well as tactical advantage and ideological considerations.

With this more complex understanding of the impact of a certain weapon and its availability to terrorists, the threat that terrorist attacks with improvised unconventional weapons can be analysed and displayed more accurately. This does not only allow for more efficacious and precise countermeasures, but also reduces ethically unsustainable behaviour of first responders and the press during a terrorist incident.

\section{The (Never-Ending) History of WMD and CBRN}

The notion of weapons of mass destruction has its origins in the middle of the twentieth century. One of the first recorded uses of the term WMD dates back to 1937 when the Archbishop of Canterbury warned against "all the new weapons of mass destruction" during his Christmas address [13], pp. 6-8. The archbishop never specified what kind of weapons he referred to in his address. Yet, researchers have been arguing that the term and the address, in general, was designed as a response to the bombing campaigns against civilians in Spain and Asia during that year [13], pp. 6-8. However, as Seth Carus argues, the Archbishop was also actively concerned with novel weapon systems like chemical warfare and could very well have referred to chemical or even biological weapons with the term weapons of mass destruction [13], p. 7.

The first politically relevant and precise notion of WMD was delivered roughly eight years after the Christmas address of the Archbishop of Canterbury. On 15 November 1945, the political leaders of the United States, Canada, and the United Kingdom issued a joint declaration calling for the regulation of atomic energy. In this declaration, the authors called amongst others "[f]or the elimination from national armaments of atomic weapons and of all other major weapons adaptable to mass destruction" (opp. cit. Carus [13], p. 8). An even more precise notion of WMD was 
defined only three years later by the United Nations Commission on Conventional Arms Control (CCA). The CCA issued an official definition of WMD and characterized this concept as chemical, biological, radiological, and nuclear (CBRN) weapons. Furthermore, the CCA opened up this definition towards potential, novel weapon systems "which have characteristics comparable in destructive effect to those of the atomic bomb or other weapons mentioned above" (opp. cit. Carus [13], pp. 9-10).

Another important part of the history of WMD and CBRN is the strategic use of the term WMD for political ends. As Michelle Bentley shows in a convincing argument, WMD has been defined and interpreted in different ways by different political actors in order to further political agendas (See Bentley [8, 9]). For example, the U.S. government and specifically the Department of Defense (DOD) appeared to favor a definition of WMD that exclusively refers to CBRN devices that are capable of mass destruction. Note that this definition would potentially exclude low-yield nuclear devices. As Bentley argues and Carus suggests, this slightly different-and ambiguous - definition had political advantages for the USA [8], pp. 392-393, [13], p. 31. Amongst others, it would enable the U.S. military to deploy low-yield nuclear weapons in space or the deep sea, although the UN Space Treaty and the Sea Bed Treaty prohibited the deployment of WMDs in space or the deep sea. Because of these changing definitions of WMD that admittedly only differed in nuances from the CBRN-based understanding of WMD, Bentley argues that WMD should be understood as a non-essentialist term rather than as a static definition. Furthermore, Carus managed to identify six different understandings of WMD in national and international discourses, of which most are based on (some) CBRN technologies [13], p. 36. The most controversial interpretations of WMD in this list (such as weapons of mass effect) will be discussed below.

\section{Abandoning WMD Altogether?}

Researchers have identified several different problems with the concept of WMD that range from conceptual issues to implementation issues in intelligence and law enforcement practice. In particular, Christian Enemark has been stressing the problems of the term "WMD". In a pivotal article for this discussion, Enemark states:

"The WMD label exaggerates the destructiveness of chemical weapons, misrepresents the problem of biological weapons, and diverts attention from the overriding importance of dealing with nuclear weapons" [25], p. 382.

This heterogeneity of weapon types summarized under the umbrella term of WMD certainly poses challenges to the concept of WMD. These challenges are even more pressing when dealing with improvised CBRN weaponry. As past incidents of use of chemical agents showed, attacks using chemical or even radiological weapons do not inflict mass casualties comparable to those casualty numbers expected for the deployment of, for example, a nuclear weapon or a weaponized biological agent (For 
cases see Danzig et al. [18]; The Times of Israel [63]). In fact, researchers have argued that, for example, improvised radiological weapons do not produce more physical impact than IEDs or other conventional weapons [36], p. 73.

Moreover, even each of the four major weapon types summarized under the term WMD seems too broad to account for terrorist weapon technologies. For example, the use of salmonella bacteria to terrorize innocent people would certainly count as improvised biological warfare but does not create the devastating consequences that a weaponized Marburg virus may be capable of. The salmonella campaign of the Rajneesh cult in 1984 is a case in point here [24], p. 59. Thus, it seems inaccurate to refer to all CBRN weapons as "weapons of mass destruction". The extent of destructiveness between these four categories, but also within each of these categories, is too diverse to group all of these weapons under the term WMD.

However, contrary to Enemark's position, one could think of at least three different arguments against the radical abandonment of WMD: First of all, it is simply impossible (and undesirable) to remove the concept of WMD from international law and diplomacy. Seth Carus shows in a detailed analysis that the term of weapons of mass destruction is an essential concept in many of the most relevant international treaties including the Chemical Weapons Convention (CWC), Biological Weapons Convention (BWC), the Nuclear Non-proliferation Treaty, the Strategic Arms Reduction Treaty (START), the Space Treaty, and the Seabed Treaty [13], pp. 6-34. Abandoning the term WMD would mean to, potentially, having to jeopardize or even renegotiate these treaties. ${ }^{1}$ Secondly, Bentley points out in a well-crafted argument that the term WMD is a non-essentialist concept that is being re-defined and used by political actors in order to further political agendas. This active role of WMD as a strategic tool in politics makes it almost impossible to abandon it from policymaking (See Bentley [8]). Lastly, it should be noted that military-grade biological, chemical, and nuclear weapons that are stockpiled and deployed by nation-states have common characteristics that could make the WMD concept useful for military strategists: For example, all three weapon categories require decontamination and extensive protective gear and all three weapon categories include strictly anti-personnel capabilities that outperform the blast radius of conventional weapons.

Yet despite the arguments in favor of keeping WMD as a concept in general, one still has to account for Enemark's criticism of diversity of impact within this concept. One possible solution would be to adopt the strongest definition of WMD as presented in Carus's article that only classifies those CBRN weapons as WMD that are, in fact, mass destructive [13], p. 36. Obviously, this classification almost immediately poses a threshold level problem: what should be considered mass destruction in this regard? One way of arguing would be to favor a potential mass destructiveness of certain CBRN weapons: while a nuclear warhead, the Novichock virus or a weaponized Marburg virus could potentially kill thousands of people in a one-off use, Salmonella

\footnotetext{
${ }^{1}$ Enemark argues against this by stating that WMD is a redundant term in international treaties that could be simply replaced by chemical, biological, or nuclear weapons. However, as Bentley has shown, the term WMD is more than a summarizing term of NBC, but a political tool. Because of this historically grown relevance of the term, it might, in fact, not be as easy to replace it in international treaties as Enemark suggests (See $[8,25,26]$.
} 
bacteria or a dirty bomb are not capable of doing so. Obviously, this interpretation of WMD is not flawless as it allows certain strategic and politically motivated exclusions or inclusions to the WMD category, as seen above. However, in light of Enemark's strong case against the concept on the one hand and good reasons to keep WMD on the other, the definition of WMD as military-grade CBRN weapons that have been in national military arsenals at some point and that are actually capable of mass destruction seems to be the least problematic choice and will be used in the next section of this chapter.

\section{WMD and Terrorism}

It is important to note that, despite massive amounts of WMD-related research and threat assessments in terrorism studies, ${ }^{2}$ WMDs (defined as military-grade CBRN weapons with mass destructive effects) are almost absent in the arsenal of the most relevant terrorist groups. Yet, not only WMDs, but even the use of the much broader weapon group of CBRN weapons in general (mass destructive or not) seems to be the exceptional more than the rule in terrorism. According to the Global Terrorism Database (GTD), the most comprehensive collection of terrorist incidents, only $0.233 \%$ of all recorded terrorist attacks were committed with CBRN weapon technologies. The majority of these cases were targeted poisonings and the use of CS or tear gas [60]. Based on an empirical assessment of terrorist attacks against the United States of America, the authors of another study note that "[b]etween 1970 and 2010, there were 751 terror attacks using conventional explosives and only 85 attacks using CBRN weapons" [24], p. 58. Moreover, the authors of this study have included very low-impact CBRN incidents such as attempted poisonings.

Furthermore, the concept of WMD, as defined above, does not encompass all mass destructive terrorist events or all terrorist weapons of mass destruction. Indeed, many of the past terrorist attacks that produced exceptionally large amounts of fatalities were executed with weapons that would not qualify as WMD as defined above. The attack on September 11, 2001, in New York City is just one (prominent) example of such weapons (See discussion in Bentley [8], p. 397). Furthermore, it has been shown in different studies that the most deadly terrorist attacks have been committed with conventional weapons such as IEDs or firearms. For instance, the authors of the recent studies on WMD terrorism in the USA that was mentioned above note in this regard:

In addition to their higher attack frequency, conventional attacks using explosives cause higher damage, on average (...) Since 1970, 216 people have died from terrorist bombings in the USA while seven individuals have died from CBRN attacks. On average, 0.28 people die per bombing campaign, while 0.08 people die per CBRN attack [24], p. 59.

In addition to this observation, a quantitative data analysis of the incidents listed in the GTD calculated both the total numbers of fatalities as well as the fatalities per

\footnotetext{
${ }^{2} \mathrm{~A}$ brief selection of published research includes [2-5, 8-10, 13, 14, 25, 26, 36, 37, 39, 45, 53, 54].
} 
attack for different weapon types used by terrorist groups (See LaFree et al. [46]). Based on this calculation, vehicle-based attacks seem to be the deadliest terrorist weapons, followed by melee weapons and firearms. According to this study, chemical weapons come in fourth and are the deadliest weapons that are commonly considered WMDs - with a total fatality number of 629. In comparison, explosive devices have a slightly lower rate of fatalities per attack but are responsible for a total amount of 99,379 deaths [46], p. 139.

Because of the absence of WMDs in terrorist incidents, one could argue that this weapon category should not have priority and should not be discussed to such an extent in terrorism research. However, next to the low probability that a terrorist group, in fact, gets their hands on a WMD, law enforcement and security agencies have been using the term WMD with regard to terrorism to stress the danger of certain non-CBRN weapons with particularly high impact. In these instances, the notion of mass destruction has arguably lowered threshold levels when referring to crimes or terrorism in comparison to the above-formulated definition of WMDs as military-grade CBRN weapons. Even a death toll in the lower hundreds caused by an improvised device could count as a WMD event in the eyes of practitioners and policymakers:

In the USA, this approach to redefine WMD for terrorism was even turned into national legislation. In the aftermath of the Oklahoma City bombing in 1998, the perpetrator of the attack, Timothy McVeigh, was sentenced to death in accordance with a by then only one-year-old reform of the US criminal code (For discussion, see Madeira [49]). According to these changes, the use of a WMD can be punished with the death sentence and WMD in this regard does not only refer to CBRN devices, but also to other "destructive devices include[ing] bombs, grenades, mines, or any gun with a barrel larger than one-half inch" (opp. cit. Carus [13], p. 29). In this reform, the term WMD does not only refer to CBRN weapons, but could better be characterized as CBRNE (chemical, biological, radiological, nuclear, and explosive). Next to Timothy McVeigh, also the shoe bomber Richard Reid as well as the perpetrators of the Boston Marathon bombing were prosecuted for using WMDs-despite the fact that all these attacks involved conventional IEDs.

The interpretation of WMDs as CBRNE is one of the most prominent proposals to cope with the challenges of the concept of WMD with regard to terrorism. Next to practical and legislative advantages, the interpretation of WMD as CBRNE in terrorist incidents also appears to be a solution to the problem that the above-defined interpretation of WMD as military-grade CBRN may be both too narrow and factually irrelevant to account for most mass-casualty terrorist attacks. By adding explosive weapons, that were used in $52.65 \%$ of all terrorist attacks listed in the GTD [60], the concept of WMD rapidly becomes a synonym for the most worrisome and most destructive weapons in terrorism - as the term traditionally promised.

Despite these obvious advantages, the treatment of WMD as CBRNE extrapolates some of the problems Enemark is raising in his article. For example, the problem that WMD includes too diverse weapon types that cannot be summarized in a single category becomes even more severe with regard to the CBRNE interpretation. The addition of explosive weapons to the definition of weapons of mass destruction 
would further broaden the concept and would, for example, refer to the nuclear bomb and to small IEDs that contain little more than pyrotechnical substances alike. Furthermore, if one would interpret explosive weapons as not only referring to IEDs but also to RPGs, mortars, grenades, and small artillery, then the category of WMD would include almost all known weapon types with the exception of small firearms and melee weapons. This interpretation of WMD seems to be too broad to be an efficacious category for both symmetrical and asymmetrical conflicts. Efficacious in this regard does not only mean that the CBRNE interpretation of WMD seems too diverse from a theoretical perspective.

It also poses serious challenges for the practitioners and institutions that work with this definition. First of all, the CBRNE definition fundamentally conflicts with the definition of WMD used in international law and numerous UN regulations and treaties. Furthermore, since the label CBRNE presents itself as a single category of (advanced) weaponry, law enforcement, and intelligence practitioners could be tempted to allocate a special branch of their work to this category. However, since the weapons summarized under this label are highly diverse, some of them need completely different resources and analysis than others. For example, countermeasures against nuclear terrorism ought to focus on global non-proliferation efforts and state-funded terrorism, while IED counter-measures are (amongst others) focused on restricting access to certain household chemicals. The CBRNE label could be falsely suggesting that the threats evolving out of these different weapon types should be treated within the same department or group of analysts.

Moreover, and relevantly for this chapter, the interpretation of WMD as CBRNE with regard to terrorism poses some serious ethical issues that can be portrayed with the help of two examples.

On June 12, 2018, German security forces stormed an apartment in Cologne and arrested the Tunisian Salafist Sief Allah H. on the basis of intelligence that he planned a terrorist attack. During the raid of his apartment, Special Forces were called in and found over 3000 castor beans that contain the organic toxin ricin. According to the German police report of this incident, Sief Allah H. had already begun to grind the seeds and had apparently attempted to combine the ricin powder with an IED (improvised explosive device) to disperse the toxin in a populated area in Cologne [56, 59, 61].

In the aftermath of this plot, Sief H's plan to construct a ricin-based IED was portrayed as a singular and exceptional case of terrorism that had the potential to kill or wound tens of thousands of persons. H's device was repeatedly called the first "bio bomb" in the history of terrorism in Germany [19]. This characterization of the incident that the German news media called the "Cologne Ricin Plot" fits all too well into the above decided interpretation of all CBRNE weapons as WMDs.

This portrayal of the ricin plot as WMD plot was visible in the journalistic reporting on the incident. In many journalistic analyses of the plot, authors described ricin as a biological weapon agent and referred to the Chemical Weapons Convention (CWC) and in the Biological Weapons Convention (BWC) of the United Nations (UN) $[51,64,67]$. This interpretation of the plot as a WMD event significantly influenced the style of reporting in the German news media. After the arrest of Sief 
Allah H., the German daily newspaper Rheinische Post published an article about the details of H's plot. In the title of this article, the author claimed that the amount of ricin that $\mathrm{H}$. produced had the potential to kill up to 13,500 persons [56]. Although German counter-terrorism forces managed to arrest $\mathrm{H}$. before he could commit the attack, the journalist reporting on the incident and the hypothetical scenarios that were formulated in the headline of the article, arguably, evoked a substantial amount of anxiety among the German public. Furthermore, one could argue that this style of reporting contributed to an erosion of public trust in the German security apparatus. The mere prospect of an attack with up to 13,500 fatalities was more than enough to spread fear and distrust in German society.

In the text of the article in Rheinische Post, the author explains that the estimate of 13,500 potential fatalities on the basis of the ricin in Sief H.'s apartment was given by a German security official. However, the author admits in a short sentence that the same official also stated that the number of 13,500 was a mathematical calculation on the basis of the $\mathrm{LD}^{50}$ value ${ }^{3}$ of ricin [56]. Yet, the $\mathrm{LD}^{50}$ value exclusively displays the lethality of a perfectly purified substance under ideal laboratory conditions. Later on in the article, the author, in effect, admits that this was an exaggeration when he stated that the interviewed security official estimated the lethality of H.'s actual ricin device to be in the low hundreds. While this death toll would still be horrific, it would not be the almost apocalyptic number of 13,500 fatalities after a single attack, as was propagated in the title of the article.

The security official that was interviewed for the article gave a differentiated estimate of the possible consequences of an actual attack with H.'s device. Yet, apparently, this estimate was not in line with the picture of a planned WMD attack that the journalist wanted to communicate with the article. Hence, he chose to use the estimate that was based on the $\mathrm{LD}_{50}$ value of ricin as the headline of the article. However, with this headline, the article clearly provided $\mathrm{H}$. with the means to greatly increase fear among the German public. This fear was in large parts generated by the WMD label that was pinned to the Cologne Ricin Plot.

The ethical issues that arises here stem from the coverage of the plot as one of WMD: In presenting H's plot as one of WMD with the potential to cause 13,500 fatalities, the press coverage likely spread significant fear through the relevant population. The issue here is that, unknowingly, the press coverage may cause caused 'soft damage', where a particular attack has population level psychological impact by means of causing widespread fear in society, a point returned to below. The issue here is that presenting the Ricin plot as one of WMD in fact aided the social impacts that $\mathrm{H}$ might have been seeking. Thus we have an ethical issue about responsibility for soft damages, and how we ought to assign that responsibility to actors other than the terrorist themselves.

Another example of these ethical challenges is the 2006 Forest Gate Raid, which was based on intelligence provided by the British intelligence agency MI5 that a

\footnotetext{
${ }^{3}$ The $\mathrm{LD}_{50}$ value refers to the lethal dose of a substance and describes how many $\mu \mathrm{g}$ (or mg) per $\mathrm{kg}$ body weight of the substance is necessary to kill 50 percent of the exposed population under laboratory conditions.
} 
radiological or chemical device was stored for an attack in two apartments in a neighbourhood of London [11]. However, during the raid this piece of intelligence turned out to be false. In fact, the two residents of the raided apartment did not have any ties to terrorism. Yet, not knowing about this false intelligence, the police arrested the residents of the apartment and one of the officers shot a resident in the chest (Independent Police Complaints Commission 2006).

Here, the anticipated, devastating consequences of a ready-to-use WMD coupled with the full-body protective gear that influenced the officer's sensory apparatus and further heightened the stress associated with the threat caused the officer to shoot the resident. As a response to this, the British prime minister Tony Blair commented on the raid as follows: "You can only imagine if they [police officers] fail to take action and something terrible happened what outcry would be then, so they are in an impossible situation" [6]. This raid was an "impossible situation" for the operatives (and the residents) since the time pressure and the stress of an already assembled WMD with its anticipated consequences forced quick response and caused mistakes and overreaction.

This has ethical relevance, as counting all CBRNE weapons as WMDs in a terrorist attack can falsely extrapolate the gravity of the situation that police officers on site might be confronted with. In case of the Forest Gate Raid, the police officers entered the apartment with the expectation to be forced to prevent an attack of tremendous destructive potential at all costs. The (implicit) labelling of all radiological or chemical devices as WMDs caused the police officers to act disproportionately.

Here the ethical implications are twofold: first, using a coarse and broad definition of WMD means that the security officials themselves perceive a particular operation as posing significant risk to them. This places unjustified stress and pressure on those security officials, which leads to the second ethical issue-in engaging with a potential target as not simply a terrorist, but one with potential WMDs, it is more than likely that the counter-terrorism response will be disproportionate to the actual objective threat that they are facing. Proportionality is a fundamental ethical principle for security actors, and so we need to be very careful with the use of terminology like WMD that might both induce and potentially be seen to justify a disproportionate response to the actual threat being faced.

Both of the above-described examples show that CBRNE definition of WMD poses serious ethical challenges in practice and is still focused on physical impact as a defining criterion. However, as will be shown below, the impact of a weapon in the hands of terrorists should not only be characterized by focusing on its capability to produce mass physical destruction. Several authors pointed out that the impact of a terrorist weapon consists of multiple different categories including, but not limited to, physical destructiveness (See e.g. Bunker [12], Dunn et al. [23]). Selected approaches to give alternative concepts to classify especially impactful terrorist weapons will be discussed in the following section. 


\section{Alternative Concepts for Terrorist Weapons of Mass Destruction}

The issues associated with mass casualty terrorist events and the definition of WMD caused several researchers, practitioners, and policymakers to rethink the conceptualization of terrorist weaponry.

One possible solution to the problem of defining WMD was proposed by Robert J. Bunker, who presented his concept of Weapons of Mass Disruption (WMD ${ }^{2}$ ) in a publication in 2000 (See Bunker [12]). In his article, Bunker points out that certain novel weapon types (including CBRN weapons like non-lethal viruses) cannot be classified as causing mass destruction. Bunker argues that these weapons target relationships and bonds on a massive scale (mass effect) in society rather than physical objects and persons [12], pp. 41-43. Therefore, these weapons might have an enormously disruptive effect despite not inflicting mass casualties or large-scale physical destruction. Clearly, Bunker's novel concept of $\mathrm{WMD}^{2}$ could be used to solve the problem that some WMDs such as radiological dispersal devices (RDDs) do not seem to be mass destructive, but rather mass disruptive in societies. However, in solving this problem, Bunker creates yet another category of weapons that is arguably as vague as WMD. The concept of $\mathrm{WMD}^{2}$ does not seem to have clear borders and threshold values with regard to effect size and extent of disruption. Thus, Bunker's solution to the problems of WMD creates even more problems with regard to vagueness and fuzzy borders between weapon categories. Furthermore, many of Bunker's examples of $\mathrm{WMD}^{2}$ weapons (i.e., radio frequency weapons, genetic alteration weapons, liquid metal embrittlement) seem even more detached from the reality of terrorist weapon choices than the traditional WMD weapon category.

Perhaps the most promising candidate concept in relation to mitigating the problems of WMD with regard to terrorism is the concept of Weapons of Mass Effect (WME). Initially proposed by William Yengst in 2008, the concept of WME is aimed at accounting for all those (terrorist) weapons that cannot be considered strictly mass destructive in the traditional sense, but that create a mass effect (See Yengst in Dunn et al. [23]). Yengst defines mass effect as an interplay of seven different criteria (Fig. 1):

According to Yengst, these criteria can be used as a rating system for terrorist weapons: only if a particular weapon reaches a certain score with each of these criteria and surpasses a certain threshold (in Yengst's analysis 41 points), then one could reasonably call this weapon a weapon of mass effect. Examples of these WMEs in Yengst's analysis are explosive attacks against critical infrastructure, the use of kinetic energy against office buildings (e.g., with an aircraft) or the contamination of drinking water supplies. With his approach to a dynamic rating system, Yengst effectively circumvented the demarcation problems resulting from static concepts such as WMD. Thereby, he solves problems such as the lacking identification of mass destruction and the high diversity of weapon types within the concept of WMD.

However, Yengst's proposal of WME does not abolish or replace the concept of WMD but rather offers an additional category of terrorist weapons for all those 

a. Fatalities and Casualties
b. Size of Area Devastated
c. Critical Infrastructure Facilities Destroyed
d. Extent of Economic Losses
e. Duration of Functional Downtime
f. Degree of Terrorism (Visible Damage, Shock, and Awe)
g. Satisfaction of Terrorist Operational Capabilities

Fig. 1 Yengst's criteria for mass effect [23], pp. [2-5] 4-5

unconventional weapon types that are not regarded WMDs in the traditional sense. While the dynamic nature of Yengst's approach does not run into the same problems as Bunker's WMD ${ }^{2}$ proposal, it does not explicitly solve the problems with the concept of WMDs, since only a few of Yengst's WME examples challenge the concept of WMD. Furthermore, Yengst's concept of WME allows for a large degree of subjectivity concerning the presumed effect of a weapon or an attack. For example, a workshop report from 2010 that used Yengst's concept portrayed the 9/11 attacks, the Popular Front for the Liberation of Palestine aircraft hijackings in the 1970s as well as the attempted assassination of Margaret Thatcher with an IED as WME attacks.

To sum up, while Yengst's approach to introduce a rating system to measure the effect (or impact) of terrorist weapons appears to be a suitable candidate to resolve a number of the problems with the concept of WMD in relation to terrorism, his introduction of the static WME concept for high-scoring weapons re-introduces some of these problems. By including or excluding certain weapon types to this concept according to varying criteria, researchers that use WME are yet again facing the problems that have been discussed above with regard to WMD. Hence, and based on Yengst's proposal, the following section will propose to expand Yengst's idea of a rating system to measure the impact of terrorist weapons. However, contrary to Yengst's approach, this new proposal does not introduce yet another concept of high-impact weapons but rather treats each and every (potential) terrorist weapon individually and based on its score in the rating system. 


\section{The Terrorist Weapon Rating System}

As seen in the last section, some researchers and practitioners have made attempts to overcome the problems arising from the traditional interpretations of WMD and CBRN. However, it also has been shown that these attempts either run into new problems or fail to resolve the original problems. However, the score-based approach of WME that was introduced by Yengst seemed to be the most promising attempt to cope with the problems that the term "WMD" poses with regard to terrorism. Hence, elements of Yengst's methodology will form the basis for my own proposal. In the following section, a dynamic rating system to identify the most dangerous terrorist weapons will be introduced.

Obviously, the term "dangerous" in this context is vague and unhelpful, at least at first glance. However, on my account dangerous will be cashed in terms of the broader concept of risk. Thus, a dangerous terrorist weapon is a weapon that poses the greatest risk to society. As several researchers already pointed out, risk is a twodimensional term that refers both to the harmful impact as well as the probability of that impact (See e.g. Forest [29]). Thus, in the cases of terrorist weapons the risk would be calculated by recourse to, firstly, the factors restricting the terrorist's decision to use a weapon and, secondly, the possible impact (or effect) that this weapon would have if used by terrorists. As already seen above, Yengst's criteria for defining WMEs are primarily aimed at one dimension of the risk that a terrorist weapon poses, namely the impact (or effect) of the weapon. However, to properly analyze this risk, both dimensions, impact and probability, are needed. Hence, the rating system in this section will not only include some of the criteria Yengst uses to assess the impact of a certain weapon but will also identify factors on the probability axis - in particular, factors that restrict the weapon choices of terrorists.

Assessing the likelihood with which a weapon might be used by terrorists is a highly complex endeavor. Terrorist groups and lone operators are agents with a wide variety of motives (both rational and irrational) who are also interested in disguising their decision-making and in deceiving researchers and investigators. Thus, a quantitative and standardized estimation of the probabilities of the use of certain weapons by terrorists is, in general, challenging. However, researchers like Gary Ackerman, Adam Dolnik, Brian Jackson, and others have identified and discussed several criteria that might influence the decision making of a terrorist group to use a specific weapon for an attack [1, 17, 21, 41]. Based on these criteria, it might be possible to give an indication as to how likely it is that a terrorist group might be successful in acquiring and using a certain weapon for an attack.

First of all, however, it is necessary to further refine the criteria to be used in assessing the impact or effect of a certain weapon in the hands of terrorists. One can, at least, identify four major criteria that contribute to the impact of a certain weapon: 


\section{(a) Hard damage}

First of all, the most visible impact that a weapon can produce is physical damage. This damage includes destruction of, and physical damage to, buildings or other structures as well as the physical harming or killing of persons and animals. However, while damage to buildings and persons can be easily characterized as physical damage, that might not be as easy with other forms of damage, such as the damage created by a cyber-attack. Since no kinetic force is used to conduct these attacks, but rather digital means such as software, it might be difficult to call the damage inflicted by a cyber-attack hard damage. ${ }^{4}$ However, I argue that, depending on the chain of consequences caused by a cyber-attack, one should characterize its damage as hard damage even if the direct damage caused by the attack might not be physical. This argument holds especially for those cyber-attacks directed at critical infrastructure. In most of these cases, the software is not the weapon itself but rather the means to turn the critical infrastructure into some sort of second-degree weapon that, via being destroyed or damaged, does physical harm to persons or damage to buildings.

In addition to physical harm or damage resulting from an attack, international organizations such as the ICRC stress that other specific harms that are not of a physical nature can have devastating destructive effects on civilian life as well. With regard to these harms, the ICRC counts (amongst others) (1) mental harm as well as (2) economic loss and displacement, as potentially having such a destructive effect [38], pp. 35-37 and 41-43.

(1) Mental harm as one possible source of damage in the aftermath of an attack is, according to the ICRC, implicitly mentioned in international humanitarian law since it forbids " (...) acts or threats of violence the primary purpose of which is to spread terror among the civilian population" (opp. cit. [38], p. 33). In this quote, "terror" refers to severe mental harm in the form of horror, psychological trauma, and post-traumatic stress.

Two important examples of such psychological reactions to terrorist attacks are anxiety and moral outrage. A terrorist attack with an advanced weapon technology or CBRN device has the potential to inflict widespread anxiety in society [2], p. 24; [3, $33,52]$. For example, public fear of possible contamination caused by improvised radiological or chemical weapons would be instances in which weapons inflict a massive degree of anxiety [44, 52, 66].

Moral outrage can be understood as the anger and horror at the severe violation of a moral standard [7], p. 155. Hence, the complex emotion of moral outrage does not only include anxiety and horror, but primary anger and disgust that can manifest in demonstrations, public condemnations of attacks or calls for justice on a collective level [43]. Arguably, those attacks performed with unconventional and globally ostracized weapons (such as chemical or biological agents) have the potential to cause a larger degree of moral outrage than, for example, an attack with a knife or gun.

\footnotetext{
${ }^{4}$ See Adam Henschke's chapter in this book on cyberterrorism and the internet of things for more on this discussion.
} 
While a certain degree of anxiety and moral outrage seems, at first glance, a proportionate reaction to an attack, and is in many cases only a temporary condition with minor influence on the impact of an attack, both anxiety and moral outrage can, depending on the nature of the attack, result in political militancy or in calls for (disproportionate) retaliation $[33,34,58]$. One effect of this could be the erosion of trust in security institutions. For example, a successful attack with an impactful weapon might harm the reputation of intelligence institutions, law enforcement, and the military since it may result in the public ceasing to trust them and their ability to keep society safe [50], p. 214; [65], p. $11 .^{5}$

(2) Economic loss and (at least temporary) displacement could add to the impact of a terrorist attack. Particularly, those attacks that involve weapon technologies capable of causing contamination of a certain area potentially cause significant economic damage [48] by means of rendering a certain area (e.g., a business or shopping buildings or streets) unusable for a long period of time. It is noteworthy that not only a de facto-contamination of a certain area would cause economic damage, but also the public fear of contamination in the aftermath of, for example, a radiological attack that was, in fact, not capable of causing any health-damaging contamination (See Khripunov [44]).

(c) Length of the attack

Not only the damage caused by an attack with a certain weapon but also the attack itself can tell a lot about the impact of said weapon. One important factor is the length of the attack in terms of the duration of use of this weapon during an attack. For example, a knife is a weapon that demands multiple uses over a long duration to create significant physical damage (i.e., to harm many people). In contrast, an IED is able to create large scale damage in a one-off use. Other than in case of a knife attack, security forces responding to an IED attack do not have any chance to interrupt or stop the attack as it happens. Hence, a weapon that creates significant damage in a very short time can be characterized as especially impactful.

\section{(d) Uncertainty of consequences}

Contrary to Yengst's approach, it may be very hard (if not impossible) to properly anticipate the damage a certain weapon will do in terms of physical, economic, and psychological damage. However, arguably the impact of a certain weapon should be considered especially high if one is unable to anticipate the consequences resulting from the use of it. This uncertainty associated with a particular weapon extrapolates its psychological damage by means of spreading large-scale fear in public. For example, the severity of the consequences from the use of pathogens as terrorist weapons is a matter of controversy among experts, yet the public believes the effects of biological weapons to be catastrophic $[42,52]$, pp. 6-7, [62]. The town of Salisbury was

\footnotetext{
${ }^{5}$ Please note that several empirical studies found that the aftermath of a terrorist attack can also have the potential to temporarily increase trust in the Government and in other members of society in general. This effect is known as the rally effect. However, recent studies showed that this effect is only a short term effect in the immediate aftermath of an attack [20, 32, 65].
} 
extensively contaminated with the most deadly chemical agent ever produced (Novichock), yet only three people were wounded as a result of this attack [27]. However, the uncertainty concerning the effects of terrorists using biological weapons makes these weapons especially effective in terms of causing psychological and other forms of soft damage. With regard to counter-measures against these weapons, security agencies often refer to the precautionary principle as a guiding approach (General discussion concerning this principle in Grunwald [35], Roeser et al. [57]).

However, the uncertainty attached to these weapons is a problem not only for the counter-terrorism authorities but also for the individual who uses them. First of all, as is the case for the authorities, the perpetrator faces a high degree of uncertainty with regard to the extent of the impact a certain, advanced weapon would have. For example, the release of a fatal virus in a shopping center might have a tremendous impact, yet the fragile nature of viruses as well as environmental conditions and other factors might diminish said impact dramatically. Secondly, the perpetrator of such an attack faces uncertainty with regard to her own security when using certain weapon types. For example, in the example above the perpetrator might very well fall victim to her own weapon during the attack against the shopping mall. This dual uncertainty makes it almost impossible to use said weapons in a controlled and discriminate manner. This uncontrollability makes these weapons even more dangerous and, hence, increases their potential impact.

So far, these four criteria only give information about what could happen if terrorists would acquire and use a certain weapon technology. However, to properly analyze the risk certain weapon types are posing, it is also necessary to consider the factors that increase or decrease the probability that terrorists might acquire and use a certain weapon. In addition to the criterion of high impact of a weapon, researchers have shown that terrorists might also consider the following criteria in choosing their weapons:

\section{(a) Availability}

The probability that a certain weapon will be used by terrorists can be seen as high if the materials that are necessary to assemble said weapon are openly available or can be acquired with little restrictions. Furthermore, the financial means that are necessary to acquire and assemble a particular weapon are part of the decisionmaking process of a terrorist group in their choice of weapons. The more affordable a weapon is, the more likely it will be acquired by small cells and lone operators [1], pp. 14, 76-82, 90, Fig. 4.1; [17], Table 2.1; [16], pp. 48-57, [21], p. 19, [31], pp. 1-13, [30], pp. 269-282, [40], pp. 198-201.

\section{(b) Required expertise}

Expertise plays a crucial role in the acquisition and use of weapons by terrorists. Some weapon types require extensive and specialized expertise to be used successfully, while others do not require deep knowledge of any kind. Here, the pre-existing expertise as well as the knowledge resources (i.e., personnel, network, safe spaces for testing) of a terrorist group deeply influence what kind of weapon will be chosen for an attack [1], pp. 14, 83, 87-88, [17], Table 2.1, [31], pp. 1-13, [30], pp. 269-282. 


\section{(c) Operational space needed}

One particularly important factor determining the expertise that is needed to successfully use a certain weapon is the sophistication of the delivery system for such a weapon ${ }^{6}$. A weapon with a specialized, complex delivery system might create a large impact, but might require a large amount of resources and considerable specialized expertise. Some weapon technologies need extensive space and specialized facilities if they are to be used in an attack. For example, the construction of an improvised nuclear device (IND) requires, at least, a laboratory with specialized equipment and facilities to store raw materials, precursors, and other materials. In a similar fashion, the handling of pathogens such as Yersinia pestis (the bacteria that causes the plague) demands laboratory conditions with suitable safety standards to avoid accidental infection. Yet, a simple IED might be manufactured in an apartment in an urban area without risking detection.

The operational space that is needed to manufacture a certain weapon type influences the weapon choices of terrorists in, at least, two ways: first of all, a large operational space such as an industrial complex, a laboratory or a remote facility requires very considerable financial resources. Secondly, a large operational space increases the risk of detection by security agencies. Potential terrorists would have to sign documents and create cover stories in order to get access to a laboratory facility. These procedures make them and their plot vulnerable to being exposed and interrupted $[4,12,16,23,28,47]$.

\section{(d) Tactical, strategical, and ideological advantage}

Last but not least, the use of a particular weapon has to have a clear tactical, strategic or ideological advantage over other weapons. Some terrorist groups have a strategy of toppling a regime by targeting specific persons and institutions, while others prefer to spread fear with mass-casualty attacks. Hence, the strategy and, consequently, the preferred tactics of a group determine the weapon choice of a terrorist group as well [1], pp. 13, 72, 99, [17], Table 2.1, [21], pp. 13-21, [41], p. 15.

However, not only tactics and strategy but also the underlining ideology of the group plays a crucial role here [1], pp. 12, 73, 83, [17], p. 44, [21], p. 70f, [22]. For example, a Marxist-Leninist terrorist group that mainly targets political figureheads might not be as interested in indiscriminate biological agents as an apocalyptic religious group that attempts to kill all "infidels".

It is important to note that all of these weapon choice criteria cannot be understood as general rules for terrorist decision-making. Rather, they should be seen as indicators for weapon choices that are highly dependent on specific ideologies, organizational structures and capabilities of terrorist groups [1, 17, 21, 41, 45]. For example, the weapon choice pattern of so-called Islamic State of Iraq and the Levant inspired lone operators in Western Europe might be completely different from the weapon choice pattern of the Revolutionary Armed Forces of Colombia (FARC) in Colombia. Hence, to accurately assess the risk that a particular weapon poses, one

\footnotetext{
6 The author expresses his gratitude to Michael L. Gross for raising this point [15].
} 
has to specify this risk by means of attaching it to a certain terrorist branch (e.g., Islamist cells or right-wing lone operators) and a region (e.g., Western Europe).

Furthermore, the assessment of the impact that a certain weapon might have cannot necessarily be generalized. To properly assess the impact of a weapon, it is important not only to avoid general weapon categorizations, such as CBRN or CBRNE, one should also avoid generalizations of weapon types such as "chemical weapon" or "explosive". Rather, one should attempt to focus on the nature and amounts of ingredients that a particular weapon consists of to arrive at a specific scenario that can be coupled with the specified weapon choice patterns of a particular group in a particular region. For example, one could assess the impact of a mediumsized improvised chemical device consisting of phosphine and estimate whether the choice patterns of a small terrorist cell in a Western democracy would be in favor of this weapon.

\section{Conclusion}

This chapter has shown that the categorization of weapon technologies using concepts like WMD runs into severe problems when applied to the phenomenon of terrorism. Hence, it was proposed to abolish the static approach that lists weapon categories with regard to the terrorist threat and, instead, to introduce a dynamic rating system to assess the risk that specific weapons pose in the hands of particular terrorist groups.

Yet, to what degree is this rating-based approach superior to the above discussed CBRNE interpretation of WMD that is (at least to some degree) currently being used in counter-terrorism practice? First of all, from a conceptual perspective, the rating approach has the advantage of giving a more detailed overview of the risk that a certain weapon type poses in the hands of a given terrorist group. Not only physical impact and casualty numbers but also soft damage and the handling of the weapon technology as well as its availability and ease of use are included in this overview. Secondly, the rating approach does not include or exclude a fixed set of weapon types. Therefore, this approach can be used to determine the risk of a wide variety of weapons that might be used by terrorists in the future. Thirdly, the approach to use a rating system for these weapons with regard to terrorism does not conflict with the existing definition of WMD in international legislation. After all, a nuclear weapon can be both a WMD according to international law and the most impactful (yet least available) terrorist weapon on the scale.

Additionally, from the point of view of practitioners and counter-terrorism institutions, the more detailed account of the presumed impact of a certain weapon in the hands of terrorists could be used to allocate resources more efficiently on particular weapon types that pose the greatest risk. After all, the counter-measures against the acquisition of an off-the-shelf nuclear weapon might be radically different from the counter-measures necessary to prevent an attack with the above-described improvised phosphine device or a crude RDD. While the first one requires international efforts of non-proliferation and the enforcement of international treaties, the latter 
one involves counter-measures such as educating and cooperating with hardware store employees or companies that produce pesticides in Western democracies on a local level. Hence, the introduced weapon rating system enables counter-terrorism institutions to group certain weapon types together dynamically and allocate specific groups of counter-measures necessary to prevent attacks using said weapons.

Finally, the above introduced rating system can help to resolve some ethical issues that arise from the use of concept (and mis-conceptualisations) of WMD in counterterrorism practice. Using the suggested rating system would prevent practitioners and other stakeholders like the press from misinterpreting terrorist plots with small amounts of toxic or radiological substances as WMD events. A more complex understanding of the impact of terrorist attacks with these substances can help to prevent disproportionate responses to threats by police forces as well as exaggerated and fear-inducing reporting by the news media in the aftermath of an attack or foiled plot.

\section{References}

1. Ackerman G (2014) "More bang for the buck": examining the determinants of terrorist adoption of new weapons technologies. King's College London (University of London)

2. Ackerman G, Jacome M (2018) WMD terrorism. PRISM 7(3):22-37

3. Ackerman GA, Pinson LE (2014) An army of one: assessing CBRN pursuit and use by lone wolves and autonomous cells. Terrorism Polit Violence 26(1):226-245. https://doi.org/10. 1080/09546553.2014.849945

4. Ackerman GA, Pereira R (2014) Jihadists and WMD: a re-evaluation of the future threat. CBRNe world, 27-34

5. Asal VH, Ackerman GA, Rethemeyer RK (2012) Connections can be toxic: terrorist organizational factors and the pursuit of CBRN weapons. Stud Conflict Terrorism 35(3):229-254. https://doi.org/10.1080/1057610X.2012.648156

6. BBC (2006) Blair defends police terror raid. BBC News. http://news.bbc.co.uk/2/hi/uk_news/ politics/5053618.stm

7. Batson CD, Chao MC, Givens JM (2009) Pursuing moral outrage: anger at torture. J. Exp. Soc. Psychol. 45(1):155-160

8. Bentley M (2012) The long goodbye: beyond an essentialist construction of WMD. Contemp Secur Policy 33(2):384-406. https://doi.org/10.1080/13523260.2012.693804

9. Bentley M (2014) Weapons of mass destruction and US foreign policy the strategic use of a concept. Taylor and Francis

10. Binder MK, Ackerman GA (2019) Pick Your POICN: introducing the profiles of incidents involving CBRN and non-state actors (POICN) database. Stud Confl Terrorism 24:1-25. https:// doi.org/10.1080/1057610X.2019.1577541

11. Brown KE (2010) Contesting the securitization of British muslims. Interventions 12(2):171182

12. Bunker RJ (2000) Weapons of mass disruption and terrorism. Terrorism Polit Violence 12(1):37-46. https://doi.org/10.1080/09546550008427548

13. Carus WS (2012) Defining weapons of mass destruction. DTIC Document

14. Carus WS (2017) A short history of biological warfare: from pre-history to the 21 st century

15. Caves Jr JP, Carus WS (2014) The future of weapons of mass destruction: their nature and role in 2030. DTIC Document 
16. Cragin, K., Daly, S. A., Everingham, S. S., Hoube, J., Kilburn, M. R., \& Marcum, C. Y. (2004). The dynamic terrorist threat: An assessment of group motivations and capabilities in a changing world. Rand Corporation.

17. Cragin K (2007) Sharing the dragon's teeth: terrorist groups and the exchange of new technologies, vol 485. Rand Corporation

18. Danzig R, Sageman M, Leighton T, Hough L, Yuki H, Kotani R, Hosford ZM (2011) Aum Shinrikyo. insights into how terrorists develop biological and chemical weapons

19. Deutsche W (2018) Die neue Sorge vor der Bio-Bombe. Dw.De. https://www.dw.com/de/dieneue-sorge-vor-der-biobombe/a-44326086

20. Dinesen PT, Jæger MM (2013) The effect of terror on institutional trust: new evidence from the 3/11 M adrid terrorist attack. Polit Psychol 34(6):917-926

21. Dolnik A (2007) Understanding terrorist innovation: technology, tactics and global trends. Routledge

22. Drake CJM (1998) The role of ideology in terrorists' target selection. Terrorism Polit Violence 10(2):53-85

23. Dunn LA, DeMarce A, Givner-Forbes R, Grosiak A, Kovner M, Lukasik SJ, Moran N, Skypek T, Yengst W, Perry JL (2008) Next generation weapons of mass destruction and weapons of mass effects terrorism, pp. [2-5] 4-5

24. Early BR, Martin EG, Nussbaum B, Deloughery K (2017) Should conventional terrorist bombings be considered weapons of mass destruction terrorism? Dyn Asymmetric Conflict 10(1):54-73. https://doi.org/10.1080/17467586.2017.1349327

25. Enemark C (2011) Farewell to WMD: the language and science of mass destruction. Contemp Secur Policy 32(2):382-400. https://doi.org/10.1080/13523260.2011.590362

26. Enemark C (2012) The unfinished business of abandoning WMD: a reply to Bentley. Contemp Secur Policy 33(2):407-412. https://doi.org/10.1080/13523260.2012.693806

27. Faulconbridge G, Holden M (2018) Explainer: the poisoning of former Russian double agent Sergei Skripal. Reuters.Com

28. Flade $F$ (2016) The Islamic state threat to Germany: evidence from the investigations. CTC Sentinel 9(7):11-14

29. Forest JJF (2012) Framework for analyzing the future threat of WMD terrorism. J Strateg Secur $5(4): 51$

30. Forest JJF (2008) Knowledge transfer and shared learning among armed groups. In: Norwitz JH (ed) Armed groups: studies in national security, counterterrorism, and counterinsurgency. Dept. of the Navy, pp 269-289

31. Forest JF (2006) Teaching terror: strategic and tactical learning in the terrorist world. Rowman \& Littlefield Publishers

32. Geys B, Qari S (2017) Will you still trust me tomorrow? The causal effect of terrorism on social trust. Public Choice 173(3):289-305

33. Gross ML, Canetti D, Vashdi DR (2016) The psychological effects of cyber terrorism. Bull At Sci 72(5): $1-8$

34. Gross ML, Canetti D, Vashdi DR (2017) Cyberterrorism: its effects on psychological wellbeing, public confidence and political attitudes. J Cybersecur 3(1):49-58

35. Grunwald A (2008) Nanoparticles: risk management and the precautionary principle. In: Jotterand F (ed) Emerging conceptual, ethical and policy issues in bionanotechnology. Springer, Netherlands, pp 85-102. https://doi.org/10.1007/978-1-4020-8649-6_6

36. House CN (2016) The chemical, biological, radiological, and nuclear terrorism threat from the Islamic state. Mil Rev 96(5):68-75

37. Hummel S (2016) The Islamic state and WMD: assessing the future threat. CTC Sentinel 9(13):18-21

38. ICRC (2016) Principle of proportionality in the rules governing the conduct of hostilities under international humanitarian law

39. Ivanova K, Sandler T (2007) CBRN attack perpetrators: an empirical study. Foreign Policy Anal 3(4):273-294. https://doi.org/10.1111/j.1743-8594.2007.00051.x 
40. Jackson BA (2001) Technology acquisition by terrorist groups: threat assessment informed by lessons from private sector technology adoption. Stud Conflict Terrorism 24(3):183-213

41. Jackson BA, Frelinger DR (2008) Rifling through the terrorists' arsenal: exploring groups' weapon choices and technology strategies. Stud Confl Terrorism 31(7):583-604

42. James LC, Oroszi TL (2015) Weapons of mass psychological destruction and the people who use them. Praeger

43. Johansen ML, Sandrup T, Weiss N (2018) Introduction: the generative power of political emotions. Conflict Soc 4(1): 1-8

44. Khripunov I (2006) The social and psychological impact of radiological terrorism. Nonproliferation Rev 13(2):275-316

45. Koehler-Derrick G, Milton DJ (2017) Choose your weapon: the impact of strategic considerations and resource constraints on terrorist group weapon selection. Terrorism Polit Violence 31:1-20. https://doi.org/10.1080/09546553.2017.1293533

46. LaFree G, Dugan L, Miller E (2014) Putting terrorism in context: lessons from the global terrorism database. Routledge

47. Lakoff A (2007) Preparing for the next emergency. Publ Cult 19(2):247

48. Lemyre L, Clément M, Corneil W, Craig L, Boutette P, Tyshenko M, Karyakina N, Clarke R, Krewski D (2005) A psychosocial risk assessment and management framework to enhance response to CBRN terrorism threats and attacks. Biosecur Bioterror 3(4):316-330

49. Madeira JL (2012) Killing McVeigh: the death penalty and the myth of closure. NYU Press

50. Meyer B (2004) Fighting terrorism-a narrow path between saving security and losing liberty. Globalization, Armed Conflicts and Security

51. Organisation for the Prohibition of Chemical Weapons (1992) Convention on the prohibition of the development, production, stockpiling and use of chemical weapons and on their destruction

52. Palmer I (2004) The psychological dimension of chemical, biological, radiological and nuclear (CBRN) terrorism. J R Army Med Corps 150(1):3-9

53. Parachini J (2003) Putting WMD terrorism into perspective. Wash Q 26(4):37-50. https://doi. org/10.1162/016366003322387091

54. Pichtel J (2011) Terrorism and WMDs. Awareness and response. CRC Press

55. Pillar PR (2006) Intelligence, policy, and the war in Iraq. Foreign Affairs, pp 15-27

56. Rheinische Post (2019) Düsseldorf: Rizin-Anschlagspläne waren weit fortgeschritten. Rheinische Post. https://rp-online.de/nrw/staedte/koeln/duesseldorf-rizin-anschlagsplaenewaren-weit-fortgeschritten_aid-39751823

57. Roeser S, Hillerbrand R, Sandin P, Peterson M (eds) (2012) Handbook of risk theory: epistemology, decision theory, ethics, and social implications of risk, vol 1. Springer Science \& Business Media

58. Shandler R, Gross ML, Backhaus S, Canetti D (2021) Cyber terrorism and public support for retaliation-a multi-country survey experiment. Brit J Polit Sci 1-19

59. Spilcker A (2018) Köln: Tunesier festgenommen: Wollte offenbar mit Giftanschlag Ungläubige töten. Focus. https://www.focus.de/politik/deutschland/koeln-er-wollte-offenbar-mit-einemgiftanschlag-die-unglaeubigen-toeten_id_9092406.html

60. (START), N. C. for the S. of T. and R. to T. (2016) Global terrorism database [Data file].

61. Staudenmaier R (2018) German police carry out more raids in Cologne after charging man with making biological weapon. Deutsche Welle. https://www.dw.com/en/german-police-carry-outmore-raids-in-cologne-after-charging-man-with-making-biological-weapon/a-44236311

62. Sullivan GR, Bongar B (2007) Psychological consequences of actual or threatened CBRNE terrorism. Psychology of terrorism, pp. 153-163

63. The Times of Israel (2015) Israel tests "dirty bombs," finds they pose no substantial danger. The Times of Israel. http://www.timesofisrael.com/israeli-tests-find-dirty-bombs-pose-no-sub stantial-danger/

64. United Nation Office of Disarmament Affairs (1975) The convention on the prohibition of the development, production and stockpiling of bacteriological (biological) and toxin weapons and on their destruction. un.org 
65. Van Der Does R, Kantorowicz J, Kuipers S, Liem M (2019) Does terrorism dominate citizens' hearts or minds? The Relationship between Fear of Terrorism and Trust in Government. Terrorism and Political Violence 1-19

66. Wessely S (2005) Don't panic! Short and long term psychological reactions to the new terrorism: the role of information and the authorities. J Ment Health 14(1):1-6. https://doi.org/10.1080/ 09638230500048099

67. Westdeutscher Rundfunk (2018) Rizin-Fund in Köln: Tunesier mischte Bio-Waffen zusammen. WDR.De.https://www1.wdr.de/nachrichten/rheinland/koeln-chorweiler-toxische-substanzen100.html

Open Access This chapter is licensed under the terms of the Creative Commons Attribution 4.0 International License (http://creativecommons.org/licenses/by/4.0/), which permits use, sharing, adaptation, distribution and reproduction in any medium or format, as long as you give appropriate credit to the original author(s) and the source, provide a link to the Creative Commons license and indicate if changes were made.

The images or other third party material in this chapter are included in the chapter's Creative Commons license, unless indicated otherwise in a credit line to the material. If material is not included in the chapter's Creative Commons license and your intended use is not permitted by statutory regulation or exceeds the permitted use, you will need to obtain permission directly from the copyright holder. 